\title{
The Role of Carbon Black on Devulcanization of Natural Rubber by Microwaves
}

\author{
Fabiula Danielli Bastos de Sousa ${ }^{a *}$, Carlos Henrique Scuracchio ${ }^{a}$ \\ ${ }^{a}$ Centro de Engenharia, Modelagem e Ciências Sociais Aplicadas - CECS, \\ Universidade Federal do ABC - UFABC, Santo André, SP, Brazil
}

Received: May 5, 2015; Revised: June 11, 2015

\begin{abstract}
One of the greatest problems of the modern society is the recycling of vulcanized elastomers, like tires and industrial rejects. This work studies one of the techniques of devulcanization of natural rubber (NR), the devulcanization by microwaves, as well as the influence of the amount of carbon black on this process through devulcanization of the NR with controlled composition on it. The samples were analyzed by Soxhlet extraction and some important correlations could be made based on its results and also by the final temperature of the samples just after the time of exposure to microwaves. The results highlighted that the increase of the temperature is responsible for the occurrence of devulcanization, which is dependent on both the amount of carbon black present in the rubber and the time of exposure to microwaves. These factors can influence its degree of devulcanization, since they are important for the absorption of energy by the material.
\end{abstract}

Keywords: $N R$, recycling, devulcanization, microwaves

\section{Introduction}

Natural rubber (NR) is naturally produced through bio-synthesis by the Hevea brasiliensis tree. It is constituted by approximately $99.99 \%$ linear cis-1,4 polyisoprene. The average molecular weight of polyisoprene in the NR ranges from 200.000 to 400.000 , with a broad distribution. As a result of this broad molecular weight distribution, NR has also a good performance during its processing ${ }^{1}$.

To acquire properties like elasticity and damping, elastomers have to go through a complex process known as vulcanization; the process in which the elastomers are mixed with chemicals to reduce their plasticity, tackiness and sensitivity to heat and cold, as well as to aggregate the useful properties such as elasticity and mechanical resistance ${ }^{2}$. This process converts, chemically, independent polymeric chains of elastomers into a three-dimensional elastic network ${ }^{1}$. However, while the vulcanization provides improvements in the properties of the elastomers and, with it, the possibility of a wide use as consumer goods, it brings difficulties for recycling after use, once the vulcanized rubber becomes a thermoset polymer, preventing its subsequent molding into another product by heating ${ }^{3}$.

Devulcanization is a way of providing energy to destroy, total or partially, the three-dimensional network formed during vulcanization ${ }^{4}$. The known methods that use different ways to promote the devulcanization of rubber include thermomechanical, thermo-chemical and mechano-chemical ${ }^{5-9}$, physical (by microwaves ${ }^{3,10-20}$ and ultrasound ${ }^{21-29}$ ) and biochemical ${ }^{30-33}$. All of them involve complex transformations that lead to depolymerization, oxidation, and in many cases, the degradation of polymeric chains of rubber, with the consequent reduction on its viscosity ${ }^{34}$.

*e-mail: fabiuladesousa@gmail.com
The microwave devulcanization is currently one of the most promising techniques, because the good properties of the devulcanized material and the possibility of high productivity. The process takes advantage of volumetric heating of the material by microwaves, promoting a more uniform heating than that achieved by more traditional methods of heating, which depend on conduction and/or convection $^{14,15,35}$. Materials behave differently when exposed to an electromagnetic field, like the one generated by microwaves. In polar materials, molecules or free ions can create a momentum of dipole, which results in the volumetric heating throughout the mass of the material. Elastomers such as NR, ethylene propylene diene monomer rubber (EPDM) and styrene-butadiene rubber (SBR) have low microwaves absorption capacity. This limitation can be overcome by the addition of a conductive filler like carbon black ${ }^{36,37}$, that induces a phenomenon known as MaxwellWagner polarization ${ }^{13,38}$. The process has physical nature, i.e. it does not involve chemicals during the process and due to this reason is named ecofriendly ${ }^{39}$. Devulcanization of elastomers by microwaves shows promising results for recycling rubber, ${ }^{3,10,12-18,40}$.

The main technique of characterization of devulcanized rubber has been through Soxhlet extraction ${ }^{41,42}$. This technique is widely mentioned by the literature to detect the status of devulcanization of elastomers s, $, 14-16,24,31,32,39,41,43-52$. In general, the content of soluble material (sol) increases with the increasing of devulcanization degree, due to the breaks of the cross-linkings and, consequently, the release of these molecules from the three-dimensional network of vulcanized rubber. Although the insoluble part (gel) still makes part of the network, typically the devulcanization process tends to decrease the cross-linkings density, making even this part more easily moldable and breakable than the original 
vulcanized rubber ${ }^{21}$. According to Yashin \& Isayev ${ }^{23}$, as a result of devulcanization, the rubber contains a significant amount of sol, that allows the rubber to be reprocessed and revulcanized in order to obtain a usable material with reasonably good mechanical properties.

Scuracchio et al. ${ }^{14,15}$ studied the characteristics of ground tire rubber (GTR) after devulcanization by microwaves at different exposure times. It was noted that, the greater the exposure time of the sample to microwaves, the greater the final temperature just after the treatment and, also, the lower the gel content verified by Soxlhet extraction. In other words, the higher the time of exposure of the rubber to microwaves, the higher its degree of devulcanization. Similar results were obtained by Zanchet et al. ${ }^{16}$, who analyzed the devulcanization of SBR by microwaves. According to the authors, the exposure time of the sample to the microwaves had a strong influence on the gel content, since for longer exposure times the material reached higher temperatures and generated materials with lower insoluble portion (gel content). A different behavior was observed by Pistor et al. ${ }^{13}$, who analyzed the properties of EPDM devulcanized by microwaves. For exposure times until 4 minutes, no significant changes in the gel content values were observed. Only exposure times to 5 minutes showed some changes in gel content.

In this work, special attention is paid to the influence of the carbon black amount present in the NR in the devulcanization process by microwaves, through the study of the devulcanization of NR with controlled composition of carbon black. It is important to bear in mind that the carbon black in the rubber is the responsible for the heating of these materials when exposed to microwaves, and the understanding of the mechanisms that occur during the devulcanization includes the role of the carbon black during the process.

\section{Experimental}

\subsection{Materials}

NR with controlled composition of carbon black $(0,20,45,60$ and 80 phr) was kindly supplied by IPAB SA. The carbon black used was type N330 according to ASTM classification (ASTM D1765-14) ${ }^{53}$. The exact composition of the samples is not known, except the amount of carbon black. All composites have the same additives and the same amount for all the samples; they are vulcanized.

\subsection{Devulcanization of NR}

NR was devulcanized in a system comprised of a conventional microwave oven adapted with a motorized stirring system with speed control ${ }^{14}$. The speed of stirring was set at $40 \mathrm{rpm}$. The devulcanization process was done by using the maximum power of the oven $(700 \mathrm{~W})$. The time at which the material was exposed to microwaves ranged from 2 to 5 minutes. The temperature after devulcanization was measured by using a rod thermometer.

The nomenclature used in this work is type NRX, where NR represents the type of rubber used and $\mathrm{X}$ represents the amount of carbon black present in the sample (in phr), ranged in 0 (NR0), 20 (NR20), 45 (NR45), 60 (NR60) and $80 \mathrm{phr}(\mathrm{NR} 80)$.

\subsection{Characterization}

Granulometric analysis of the samples of NR0 and NR80 was performed according to ASTM D5644-01 ${ }^{[54]}$.

In order to verify the influence of the amount of carbon black and the exposure time of NR to microwaves on devulcanization, gel content of devulcanized NR with controlled composition of carbon black was analyzed by performing Soxhlet extraction, by using toluene as solvent. The extraction time was $24 \mathrm{~h}$ and it was performed by using approximately $5 \mathrm{~g}$ of material. After the extraction, the material and the thimble filter were dried for $24 \mathrm{~h}$ at $80^{\circ} \mathrm{C}$ and its mass was measured.

\section{Results and Discussion}

\subsection{Granulometry}

The granulometric analysis of the NR0 and NR80 is shown in the Figure 1.

According to the Figure 1, it can be seen that the NR80 has a more refined granulometry in comparison to the compound NR0. Due to the presence of carbon black in NR80, rubber was probably more rigid and, thereby, easier to grind, resulting in a rubber with smaller particle sizes. So, the higher stiffness promoted by the presence of carbon black in the vulcanized sample, the easier the grinding process.

However, the difference of the particle sizes (Figure 1) is supposed not to have a significant effect on the devulcanization process, since the microwave heating is volumetric and less dependent on heat conduction.

\subsection{Temperature measurements after treatment}

Temperatures of the NR with controlled composition of carbon black after the time of exposure to microwaves are shown in Table 1.

In general, it can be observed the increase of the temperature of the samples with the increase of the time of exposure to microwaves, as also observed by other authors ${ }^{3,14,15,18}$. Besides, it can be verified a trend towards the increase of the temperature of NR after the treatment as the amount of

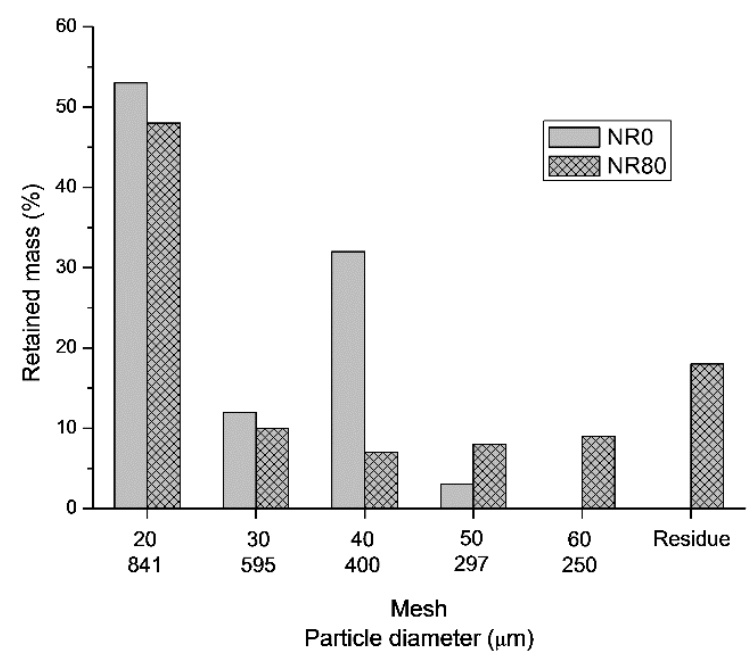

Figure 1. Granulometric analysis of the NR0 and NR80. 
carbon black in the rubber got higher. As carbon black is a conductive filler ${ }^{13,36,37}$, it can absorb microwave radiation and converts this energy into heat ${ }^{3,18}$. So, by increasing the amount of carbon black in the NR, more microwave energy is absorbed.

Even in the sample containing no carbon black, heating was observed, but it was much smaller in comparison to the samples containing this filler. The heating of the NR0 probably happened due to the presence of some residue of any other chemical substance used during vulcanization, since the real composition of the rubber is not known.

\subsection{Gel content}

Table 2 shows the results of Soxhlet extraction of the samples.

As mentioned before, extraction technique is able to separate the insoluble fraction of the rubber (known as gel fraction - vulcanized part) of the soluble fraction (sol fraction - devulcanized part). So, the gel content is an index to evaluate the degree of vulcanization of the rubbers ${ }^{18}$. In general, the higher the sol fraction, the more efficient the devulcanization process is ${ }^{5,15,55}$

According to the Table 2, in general, it could be observed that the gel contend decreased with the increasing of the exposure time of the NR to microwaves, as well as with the increasing of carbon black content present in the sample. These results show that the vulcanized rubbers were devulcanized by the action of microwaves, and the carbon black acting as a conductive filler was really efficient, increasing the efficiency of the process in the samples as its content increases.

It is important to point out that, during heating, the oil can evaporate when the rubber reaches high temperatures. As the exact quantity of oil is the one detected for the untreated sample, the value of the soluble phase can be even greater than the one obtained through the analysis of Soxhlet extraction, being that the process has been, in fact, more efficient. According to Scuracchio et al. ${ }^{14}$, the existence of some part soluble in toluene even for the sample with no treatment by microwaves is probably due to the presence of auxiliary process oils in the rubber.

The interaction of charged particles in some materials with the electric field component of electromagnetic radiation causes heating on the material ${ }^{38}$. Carbon black presents a sufficient electrical conductivity to promote this interaction between the wave and the material ${ }^{36}$. In the case of dielectric solid materials with charged particles, which are free to move in a delimited region of the material (such as $\pi$-electrons in carbon black), a current traveling in phase with the electromagnetic field is induced. As the electrons cannot couple to the changes of phase of the electric field, heat is the result of dissipated energy (Maxwell-Wagner effect ${ }^{56,57}$ ).

The ability of a microwave absorber material to be heated in the presence of a microwave field is defined by its dielectric loss tangent (Equation 1):

$\tan \delta=\varepsilon^{\prime \prime} / \varepsilon^{\prime}$

The dielectric loss tangent is composed of two parameters, the dielectric constant (or real permittivity), $\varepsilon^{\prime}$, and the dielectric loss factor (or imaginary permittivity), $\varepsilon^{\prime \prime} . \varepsilon$ ' quantifies the efficiency with which the electromagnetic energy is converted to heat ${ }^{38,58,59}$. The $\tan \delta$ value of carbon black is between $0.35-0.83^{60,61}$.

Pistor et al. ${ }^{12}$ studied the devulcanization of EPDM by microwaves and the influence of paraffinic oil in the process. They observed higher temperatures in the samples without paraffinic oil due to an increase in carbon black content and absence of evaporation or degradation of oil. According to the authors, carbon black has high thermal conductivity and heat capacity, what permit greater accumulation of internal energy and a better distribution of energy in the material. In the same way, some authors analyzed the conductivity of elastomers or blends based on elastomers containing carbon black. The conductivity got higher as the amount of filler present in the samples increased ${ }^{62-67}$, especially after

Table 1. Temperatures of the samples immediately after the microwaves treatment.

\begin{tabular}{cccccc}
\hline $\begin{array}{c}\text { Exposure time of } \\
\text { NR to microwaves }\end{array}$ & \multicolumn{5}{c}{ Temperature $\left({ }^{\circ} \mathbf{C}\right)$} \\
\cline { 2 - 6 }$(\mathbf{m i n})$ & NR0 & NR20 & NR45 & NR60 & NR80 \\
\hline 2 & 56 & 66 & 101 & 109 & 166 \\
3 & 74 & 94 & 153 & 175 & 244 \\
4 & 80 & 117 & 185 & 271 & 250 \\
5 & 103 & 138 & 217 & 280 & 307 \\
\hline
\end{tabular}

Table 2. Gel content of the samples of NR with controlled composition of carbon black.

\begin{tabular}{|c|c|c|c|c|c|}
\hline \multirow{2}{*}{$\begin{array}{l}\text { Exposure time of } \\
\text { NR to microwaves } \\
(\text { min) }\end{array}$} & \multicolumn{5}{|c|}{ Gel content $(\%)$} \\
\hline & NR0 & NR20 & NR45 & NR60 & NR80 \\
\hline 0 & 83.04 & 80.38 & 89.52 & 82.70 & 80.09 \\
\hline 2 & 79.19 & 80.31 & 82.26 & 79.77 & 79.66 \\
\hline 3 & 78.43 & 79.37 & 79.91 & 76.74 & 64.93 \\
\hline 4 & 78.29 & 78.82 & 77.71 & 65.45 & 59.17 \\
\hline 5 & 77.51 & 77.84 & 60.32 & 53.61 & 55.09 \\
\hline
\end{tabular}


achieving the percolation threshold, showing its efficiency as a conductive filler.

The presented results are in agreement with other authors ${ }^{3,18,68}$, who studied the influence of variation of the carbon black content present in SBR on its devulcanization by microwaves. According to them, the degree of devulcanization by microwaves is proportional to the amount of carbon black on the rubber. In other words, the electrical conductivity of rubber increases with the increase of the amount of carbon black due to the higher energy absorbance.

In order to deepen the analysis of the results, Figure 2 presents the correlation between temperature of the samples after exposure to microwaves and gel content.

From the results presented in the Figure 2, a correlation between the temperature of the samples just after the treatment and the gel content obtained by Soxhlet extraction technique can be seen. In general, the higher the final temperature of the sample, the smaller its gel content, what proves that the devulcanization of the rubber was obtained. Then, the temperature rise is responsible for the occurrence of devulcanization. According to Hirayama \& Saron ${ }^{18}$, "the heating of material, due to the presence of carbon black, is the main factor that leads to devulcanization, which is confirmed by an increase in the temperature of the rubber as a function of carbon black content in the material". Based on the results found, it could be concluded that the time of exposure of the sample to microwaves has also great value, what can be highlighted from the analysis of the Figure 3.

According to the Figure 3, it is clear the dependence of the degree of devulcanization with the time of exposure of NR to microwaves. The devulcanization process is efficient from 3 minutes (or more) of exposure to microwaves, and depending on the content of carbon black present in the sample, the efficiency level of the process can be improved.

According to some authors ${ }^{3,18}$, the degree of devulcanization (Equation 2) can be calculated by the difference between gel content of the devulcanized rubber (DR) and the one of vulcanized rubber (VR).

Degree of devulcanization $=-(D R-V R)$

The results of the degree of devulcanization of the NR with controlled composition of carbon black are showed in the Figure 4. It is noted, in general, that there is a tendency of the increase of the degree of devulcanization values as function of the amount of carbon black present in the rubber, and as function of the increasing of the exposure time of NR to microwaves. In addition, according to the Figures 2 and 3, it could be observed that the relevant amount of carbon black able to improve the process of devulcanization by microwaves is from $45 \mathrm{phr}$. Smaller quantities seem not to have influence on the process. According to Paulo et al. ${ }^{3}$, the amount of carbon black is an important factor to achieve a successful recycling by using devulcanization by microwaves.

As the increase of the final temperature of the compound is the responsible for devulcanization, the amount of carbon black and exposure time of the sample to microwaves are able to cause its increase, which is reflected in the degree of devulcanization. The final temperature reached by the sample is the determining factor for the degree of devulcanization, being dependent on the time of exposure of the sample to microwaves and the amount of carbon black present on it.

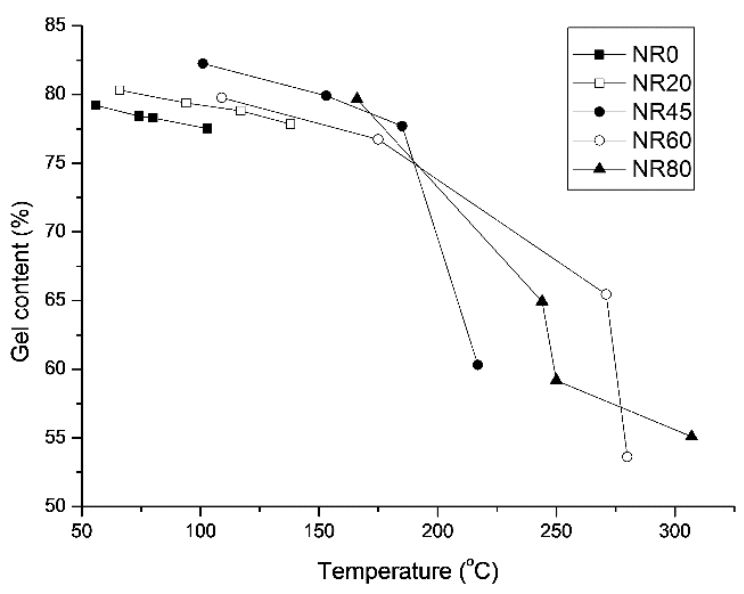

Figure 2. Gel content versus temperature of the samples after exposure to microwaves.

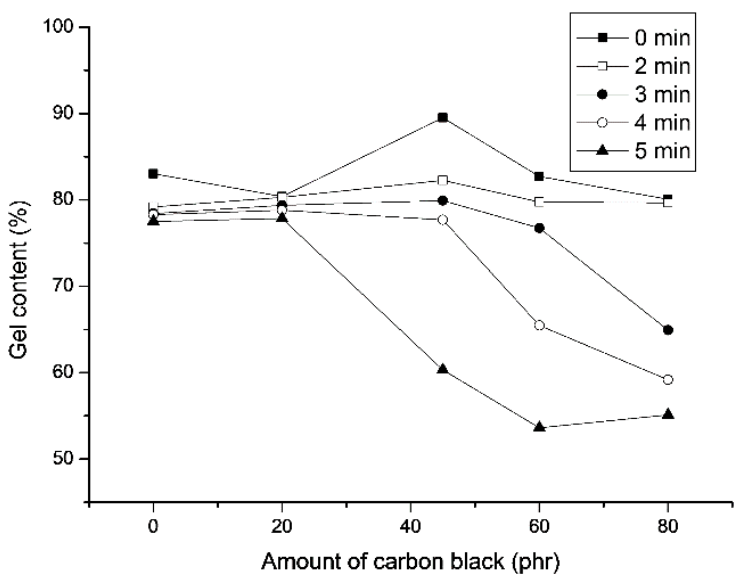

Figure 3. Gel content versus amount of carbon black of the samples after different times of exposure to microwaves.

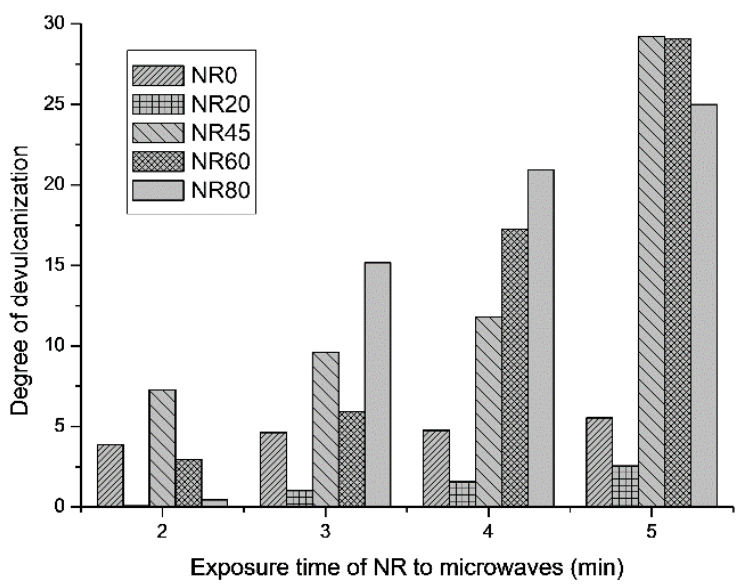

Figure 4. Degree of devulcanization of the NR with controlled composition of carbon black. 


\section{Conclusions}

The compound containing carbon black (NR80) was easily ground and presented a more refined granulometry in comparison to the compound containing no carbon black (NR0).

The amount of carbon black present in the rubber, as well as the time of exposure of NR to microwaves, are able to influence its devulcanization degree. The temperature of the NR, immediately after the time of exposure to microwaves, increased as the amount of carbon black present in the sample, as well as the time of exposure to microwaves got higher. As the increase of the temperature is the responsible for the

\section{References}

1. Ignatz-Hoover F and To BH. Rubber compounding: chemistry and applications. New York: Marcel Dekker; 2004.

2. Arrillaga A, Zaldua AM, Atxurra RM and Farid AS. Techniques used for determining cure kinetics of rubber compound. European Polymer Journal. 2007; 43(11):4783-4799. http:// dx.doi.org/10.1016/j.eurpolymj.2007.08.024.

3. Paulo GD, Hirayama D and Saron C. Microwave devulcanization of waste rubber with inorganic salts and nitric acid. Advanced Materials Research. 2012; 418-420:1072-1075. http://dx.doi. org/10.4028/www.scientific.net/AMR.418-420.1072.

4. Sun XM and Isayev AI. Continuous ultrasonic devulcanization comparison of carbon black filled synthetic isoprene and natural rubbers. Rubber Chemistry and Technology. 2008; 81(1):19-46. http://dx.doi.org/10.5254/1.3548195.

5. Zhang XX, Lu ZX, Tian D, Li H and Lu CH. Mechanochemical devulcanization of ground tire rubber and its application in acoustic absorbent polyurethane foamed composites. Journal of Applied Polymer Science. 2013; 127(5):4006-4014. http:// dx.doi.org/10.1002/app.37721.

6. De D and De D. Processing and material characteristics of a reclaimed ground rubber tire reinforced styrene butadiene rubber. Materials Sciences and Applications. 2011; 2(5):486495. http://dx.doi.org/10.4236/msa.2011.25066.

7. Maridass B and Gupta BR. Performance optimization of a counter rotating twin screw extruder for recycling natural rubber vulcanizates using response surface methodology. Polymer Testing. 2004; 23(4):377-385. http://dx.doi.org/10.1016/j. polymertesting.2003.10.005.

8. Maridass B and Gupta BR. Process optimization of devulcanization of waste rubber powder from syringe stoppers by twin screw extruder using response surface methodology. Polymer Composites. 2008; 29(12):1350-1357. http://dx.doi.org/10.1002/pc.20379.

9. Yazdani H, Karrabi M, Ghasmi I, Azizi H and Bakhshandeh GR. Devulcanization of waste tires using a twin-screw extruder: The effects of processing conditions. Journal of Vinyl \& Additive Technology. 2011; 17(1):64-69. http://dx.doi.org/10.1002/ vnl.20257.

10. Bani A, Polacco G and Gallone G. Microwave-induced devulcanization for poly(ethylene-propylene-diene) recycling. Journal of Applied Polymer Science. 2011; 120(5):2904-2911. http://dx.doi.org/10.1002/app.33359.

11. Pistor V and Zattera AJ. Degradation kinetics of ethylene propylene diene terpolymer residues devulcanized by microwaves. Journal of Elastomers and Plastics. 2012; 44:1-15.

12. Pistor V, Scuracchio $\mathrm{CH}$, Oliveira PJ, Fiorio R and Zattera AJ. Devulcanization of ethylene-propylene-diene polymer residues by microwave-influence of the presence of paraffinic occurrence of devulcanization, both factors are important. The gel content of the samples decreased as the treatment time and carbon black content increased.

\section{Acknowledgements}

The authors would like to thank IPAB SA for the material donation; Materials Department of Escola de Engenharia de Lorena (EEL - USP) and Materials Department of Universidade Federal de São Carlos (DEMa - UFSCar) for the laboratory facilities; and FAPESP (process number $03 / 08175-2$ ) for the financial support.

oil. Polymer Engineering and Science. 2011; 51(4):697-703. http://dx.doi.org/10.1002/pen.21875.

13. Pistor V, Ornaghi FG, Fiorio R, Zattera AJ, Oliveira PJ and Scuracchio CH. Devulcanization of ethylene-propylene-diene polymer residues (EPDM-r) by microwaves. Polimeros: Ciência e Tecnologia. 2010; 20(3):165-169.

14. Scuracchio CH, Waki DA and Bretas RES. Caracterização térmica e reológica de borracha de pneu desvulcanizada por microondas. Polímeros: Ciência e Tecnologia. 2006; 16(1):4652.

15. Scuracchio CH, Waki DA and da Silva M. Thermal analysis of ground tire rubber devulcanized by microwaves. Journal of Thermal Analysis and Calorimetry. 2007; 87(3):893-897. http://dx.doi.org/10.1007/s10973-005-7419-8.

16. Zanchet A, Carli LN, Giovanela M, Crespo JS, Scuracchio $\mathrm{CH}$ and Nunes RCR. Characterization of microwavedevulcanized composites of ground SBR scraps. Journal of Elastomers and Plastics. 2009; 41(6):497-507. http://dx.doi. org/10.1177/0095244309345411.

17. Zanchet A, Carli LN, Giovanela M, Brandalise RN and Crespo JS. Use of styrene butadiene rubber industrial waste devulcanized by microwave in rubber composites for automotive application. Materials \& Design. 2012; 39:437-443. http:// dx.doi.org/10.1016/j.matdes.2012.03.014.

18. Hirayama D and Saron C. Chemical modifications in styrenebutadiene rubber after microwave devulcanization. Industrial \& Engineering Chemistry Research. 2012; 51(10):3975-3980. http://dx.doi.org/10.1021/ie202077g.

19. Kleps T, Piaskiewicz M and Parasiewicz W. The use of thermogravimetry in the study of rubber devulcanization. Journal of Thermal Analysis and Calorimetry. 2000; 60(1):271-277. http://dx.doi.org/10.1023/A:1010134315762.

20. Landini L, de Araujo SG, Lugao AB and Wiebeck H. Preliminary analysis to BIIR recovery using the microwave process. European Polymer Journal. 2007; 43(6):2725-2731. http:// dx.doi.org/10.1016/j.eurpolymj.2007.03.017.

21. Scuracchio $\mathrm{CH}$, Bretas RES and Isayev AI. Blends of PS with SBR devulcanized by ultrasound: Rheology and morphology. Journal of Elastomers and Plastics. 2004; 36(1):45-75. http:// dx.doi.org/10.1177/0095244304039913.

22. Ghose S, Isayev AI and von Meerwall E. Effect of ultrasound on thermoset polyurethane: NMR relaxation and diffusion measurements. Polymer. 2004; 45(11):3709-3720. http://dx.doi. org/10.1016/j.polymer.2004.03.053.

23. Yashin VV and Isayev AI. The effect of polydispersity on structure of ultrasonically treated rubbers. Polymer. 2004; 45(17):60836094. http://dx.doi.org/10.1016/j.polymer.2004.06.029. 
24. Feng WL and Isayev AI. High-power ultrasonic treatment of butyl rubber gum: structure and properties. Journal of Polymer Science. Part B, Polymer Physics. 2005; 43(3):334-344. http:// dx.doi.org/10.1002/polb.20331.

25. Feng WL and Isayev AI. Blends of ultrasonically devulcanized tire-curing bladder and butyl rubber. Journal of Materials Science. 2005; 40(11):2883-2889. http://dx.doi.org/10.1007/ s10853-005-2423-8.

26. Isayev AI and Sujan B. Nonisothermal vulcanization of devulcanized GRT with reversion type behavior. Journal of Elastomers and Plastics. 2006; 38(4):291-318. http://dx.doi. org/10.1177/0095244306067424.

27. Massey JL, Parr JC, Wagler TA, von Meerwall E, Hong CK and Isayev AI. Ultrasound devulcanization of unfilled natural rubber networks, studied via component molecular mobility. Polymer International. 2007; 56(7):860-869. http://dx.doi. org/10.1002/pi.2216.

28. Sun $X$ and Isayev AI. Ultrasound devulcanization: comparison of synthetic isoprene and natural rubbers. Journal of Materials Science. 2007; 42(17):7520-7529. http://dx.doi.org/10.1007/ s10853-007-1623-9.

29. Hong CK and Isayev AI. Plastic/rubber blends of ultrasonically devulcanized GRT with HDPE. Journal of Elastomers and Plastics. 2001; 33(1):47-71. http://dx.doi.org/10.1106/5AMQXEAY-A05B-P1FY

30. Li YH, Zhao SH, Zhang LQ, Wang YQ and Yu WY. The effect of different $\mathrm{Fe} 2+$ concentrations in culture media on the recycling of ground tyre rubber by Acidithiobacillus ferrooxidans YT-1. Annals of Microbiology. 2013; 63(1):315-321. http://dx.doi. org/10.1007/s13213-012-0476-x.

31. Li YH, Zhao SH and Wang YQ. Microbial desulfurization of ground tire rubber by sp.: a novel technology for crumb rubber composites. Journal of Polymers and the Environment. 2012; 20(2):372-380. http://dx.doi.org/10.1007/s10924-011-0386-1.

32. Li YH, Zhao SH and Wang YQ. Microbial desulfurization of ground tire rubber by Thiobacillus ferrooxidans. Polymer Degradation \& Stability. 2011; 96(9):1662-1668. http://dx.doi. org/10.1016/j.polymdegradstab.2011.06.011.

33. Yao C, Zhao SH, Hu MH, Wang BW and Zhang LQ. Halfsubmerged cultivation method for the microbial desulfurization of waste latex rubber. Journal of Applied Polymer Science. 2014; 131(21):1-9. http://dx.doi.org/10.1002/app.41039.

34. Sienkiewicz M, Kucinska-Lipka J, Janik H and Balas A. Progress in used tyres management in the European Union: a review. Waste Management. 2012; 32(10):1742-1751. http:// dx.doi.org/10.1016/j.wasman.2012.05.010. PMid:22687707.

35. Novotny DS, Marsh RI, Masters FC and Tally DN. Microwave devulcanization of rubber. US 4,104,205. 1978 Ago 1.

36. Amari T, Themelis NJ and Wernick IK. Resource recovery from used rubber tires. Resources Policy. 1999; 25(3):179-188. http://dx.doi.org/10.1016/S0301-4207(99)00025-2.

37. Sun X, Isayev AI, Joshi TR and von Meerwall E. Molecular mobility of unfilled and carbon-black-filled isoprene rubber: Proton NMR transverse relaxation and diffusion. Rubber Chemistry and Technology. 2007; 80(5):854-872. http://dx.doi. org/10.5254/1.3539421.

38. Menéndez JA, Arenillas A, Fidalgo B, Fernandez Y, Zubizarreta L, Calvo EG, et al. Microwave heating processes involving carbon materials. Fuel Processing Technology. 2010; 91(1):1-8. http://dx.doi.org/10.1016/j.fuproc.2009.08.021.

39. Hong YJ, Jeong KM, Saha P, Suh J and Kim JK. Processing and characterization of microwave and ultrasonically treated waste-EPDM/LDPE polymer composites. Polymer Engineering and Science. 2015; 55(3):533-540. http://dx.doi.org/10.1002/ pen.23916.

40. Pistor V and Zattera AJ. Degradation kinetics of ethylene propylene diene terpolymer residues devulcanized by microwaves. Journal of Elastomers and Plastics. 2014; 46(1):69-83. http:// dx.doi.org/10.1177/0095244312462159.

41. Levin VY, Kim SH, Isayev AI, Massey J and von Meerwall E. Ultrasound devulcanization of sulfur vulcanized SBR: Crosslink density and molecular mobility. Rubber Chemistry and Technology. 1996; 69(1):104-114. http://dx.doi.org/10.5254/1.3538350.

42. Isayev AI, Kim SH and Levin VY. Superior mechanical properties of reclaimed SBR with bimodal network. Rubber Chemistry and Technology. 1997; 70(2):194-201. http://dx.doi. org/10.5254/1.3538424.

43. Li YH, Zhao SH and Wang YQ. Improvement of the properties of natural rubber/ground tire rubber composites through biological desulfurization of GTR. Journal of Polymer Research. 2012; 19(5):9864. http://dx.doi.org/10.1007/s10965-012-9864-y.

44. Isayev AI, Chen J and Tukachinsky A. Novel ultrasonic technology for devulcanization of waste rubbers. Rubber Chemistry and Technology. 1995; 68(2):267-280. http://dx.doi. org/10.5254/1.3538741.

45. Tukachinsky A, Schworm D and Isayev AI. Devulcanization of waste tire rubber by powerful ultrasound. Rubber Chemistry and Technology. 1996; 69(1):92-103. http://dx.doi. org/10.5254/1.3538362.

46. Hong CK and Isayev AI. Continuous ultrasonic devulcanization of carbon black-filled NR vulcanizates. Journal of Applied Polymer Science. 2001; 79(13):2340-2348. http://dx.doi.org/10.1002/10974628(20010328)79:13<2340::AID-APP1042>3.0.CO;2-4.

47. Oh JS and Isayev AI. Continuous ultrasonic devulcanization of unfilled butadiene rubber. Journal of Applied Polymer Science. 2004; 93(3):1166-1174. http://dx.doi.org/10.1002/app.20508.

48. Oh JS, Ghose S and Isayev AI. Effects of ultrasonic treatment on unfilled butadiene rubber. Journal of Polymer Science. Part B, Polymer Physics. 2003; 41(22):2959-2968. http://dx.doi. org/10.1002/polb.10606.

49. Oh JS, Isayev AI, Wagler T, Rinaldi PL and Von Meerwall E. Molecular mobility and structure of ultrasonically treated unfilled butadiene rubber. Journal of Polymer Science. Part B, Polymer Physics. 2004; 42(10):1875-1887. http://dx.doi. org/10.1002/polb.20072.

50. Shim SE and Isayev AI. Effects of the presence of water on ultrasonic devulcanization of polydimethylsiloxane. Journal of Applied Polymer Science. 2003; 88(11):2630-2638. http:// dx.doi.org/10.1002/app.12004.

51. Shim SE, Parr JC, von Meerwall E and Isayev AI. NMR relaxation and pulsed gradient NMR diffusion measurements of ultrasonically devulcanized poly (dimethylsiloxane). The Journal of Physical Chemistry B. 2002; 106(46):12072-12078. http://dx.doi.org/10.1021/jp0257247.

52. Zhang XX, Lu CH and Liang M. Properties of natural rubber vulcanizates containing mechanochemically devulcanized ground tire rubber. Journal of Polymer Research. 2009; 16(4):411-419. http://dx.doi.org/10.1007/s10965-008-9243-x.

53. American Society for Testing and Materials - ASTM. ASTM D1765-14: standard classification system for carbon blacks used in rubber products. West Conshohocken; 2014.

54. American Society for Testing and Materials - ASTM. ASTM D5644-01: standard test methods for rubber compounding materials: determination of particle size distribution of recycled vulcanizate particulate rubber. West Conshohocken; 2001. 
55. Hassan MM, Aly RO, Abdel Aal SE, El-Masry AM and Fathy ES. Mechanochemical devulcanization and gamma irradiation of devulcanized waste rubber/high density polyethylene thermoplastic elastomer. Journal of Industrial and Engineering Chemistry. 2013; 19(5):1722-1729. http://dx.doi.org/10.1016/j. jiec.2013.02.012.

56. Meredith R. Engineers' handbook of industrial microwave heating. London: The Institution of Electrical Engineers; 1998. http://dx.doi.org/10.1049/PBPO025E.

57. Zlotorzynski A. The application of microwave-radiation to analytical and environmental chemistry. Critical Reviews in Analytical Chemistry. 1995; 25(1):43-76. http://dx.doi. org/10.1080/10408349508050557.

58. Leonelli C and Mason TJ. Microwave and ultrasonic processing: now a realistic option for industry. Chemical Engineering and Processing. 2010; 49(9):885-900. http://dx.doi.org/10.1016/j. cep.2010.05.006.

59. Thostenson ET and Chou TW. Microwave processing: fundamentals and applications. Composites. Part A, Applied Science and Manufacturing. 1999; 30(9):1055-1071. http:// dx.doi.org/10.1016/S1359-835X(99)00020-2.

60. Atwater KE and Wheeler RR Jr. Temperature dependent complex permittivities of graphitized carbon blacks at microwave frequencies between 0.2 and $26 \mathrm{GHz}$. Journal of Materials Science. 2004; 39(1):151-157. http://dx.doi. org/10.1023/B:JMSC.0000007739.07797.08.

61. Ma JX, Fang M, Li P, Zhu B, Lu XH and Lau NT. Microwaveassisted catalytic combustion of diesel soot. Applied Catalysis A, General. 1997; 159(1-2):211-228. http://dx.doi.org/10.1016/ S0926-860X(97)00043-4.

62. Alam MK, Islam MT, Mina MF and Gafur MA. Structural, mechanical, thermal, and electrical properties of carbon black reinforced polyester resin composites. Journal of Applied Polymer Science. 2014; 131(13):n/a. http://dx.doi.org/10.1002/ app.40421.

63. Ma LF, Bao RY, Dou R, Liu ZY, Yang W, Xie BH, et al. A high-performance temperature sensitive $\mathrm{TPV} / \mathrm{CB}$ elastomeric composite with balanced electrical and mechanical properties via PF-induced dynamic vulcanization. Journal of Materials Chemistry. A, Materials for Energy and Sustainability. 2014; 2(40):16989-16996. http://dx.doi.org/10.1039/C4TA03833A.

64. Sae-Oui P, Thepsuwan U, Thaptong P and Sirisinha C. Comparison of reinforcing efficiency of carbon black, conductive carbon black, and carbon nanotube in natural rubber. Advances in Polymer Technology. 2014; 33(4):n/a. http://dx.doi.org/10.1002/ adv.21422.

65. Thaptong P, Sirisinha C, Thepsuwan U and Sae-Oui P. Properties of natural rubber reinforced by carbon black-based hybrid fillers. Polymer-Plastics Technology and Engineering. 2014; 53(8):818-823. http://dx.doi.org/10.1080/03602559.2014.886 047.

66. Kwon SK, Ahn JM, Kim GH, Chun CH, Hwang JS and Lee JH. Microwave absorbing properties of carbon black/silicone rubber blend. Polymer Engineering and Science. 2002; 42(11):21652171. http://dx.doi.org/10.1002/pen.11106.

67. Ghosh P and Chakrabarti A. Conducting carbon black filled EDPM vulcanizates: assessment of dependence of physical and mechanical properties and conducting character on variation of filler loading. European Polymer Journal. 2000; 36(5):10431054. http://dx.doi.org/10.1016/S0014-3057(99)00157-3.

68. Hirayama D and Saron C. Moagem e desvulcanização por micro-ondas da borracha estireno-butadieno (SBR). Revista Eletrônica de Materiais e Processos. 2012; 7(1):34-38. Available from: <www.dema.ufcg.edu.br>. Access in: 29/04/2015. 